Editorial

\title{
Re-Paving the Road Built by Chemistry: A Challenge to Biochemistry and Biotechnology
}

\author{
Alberto A. Iglesias \\ Instituto de Agrobiotecnología del Litoral (CONICET-UNL), Laboratorio de Enzimología Molecular, FBCB, Paraje "El \\ Pozo", 3000 Santa Fe, Argentina
}

Biochemistry's birth can be placed at the end of the nineteenth century, when Eduard Buchner made a clever interpretation of experimental observations on the generation of gas bubbles after addition (the original purpose was preservation) of sucrose to a yeast crude extract (Lagerkvist, 2005). Intelligently, Buchner concluded that the disaccharide had been fermented by broken cells' suspension to produce $\mathrm{CO}_{2}$, as it would have happened in intact yeast. This finding revealed the fallacy of the vitalist theory, thus opening the door to biochemistry, which emerged with the challenge to identify structure and function of cell molecular components. The characterization of many biomolecules and the discovery of diverse metabolic routes constitute significant achievements obtained in the first half of the twentieth century (Nelson and Cox, 2013). Later, the elucidation of the double-helix DNA structure by Watson and Crick (1953) and works by Ochoa and Kornberg making clear the action mechanisms of enzymes that process nucleic acids (Nobel Media AB, 2014), gave a new perspective in biosciences. The emergence of the so-called molecular biology established an approach to characterize structural components that appropriately complement with those from biochemistry. The combination of both strategies potentiated the capacity to gain data on structure-function relationships that are critical for the understanding of cellular processes. This allowed us to reach the huge advance in knowledge in biosciences that we now dispose.

Organic chemistry experienced stunning developments throughout the nineteenth and twentieth centuries. To a large degree, the advance of chemistry (that had been started earlier as a science) took place separately and with scarce (if any) links to biological chemistry. The accomplishments singularly obtained in the areas of chemistry of synthesis and petrochemstry (Yeh and Lim, 2007) strongly modified manufacturing processes after the industrial revolution. This consolidated a means to produce many materials and compounds that provide most of the goods and services of high technological standard in modern human society. Nevertheless, together with the success reached from refining petroleum and the synthesis of novel and helpful molecules, a crucial obstacle arose because of lack of sustainability and care respect to environmental conservation (Joyce and Stewart, 2012). Three main facts result in a critical scenario. One (and merely) is that oil reserves are limited and, sooner of later, they will run out. Also, materials currently utilized are highly recalcitrant to degradation, complicating their disposal or recycling. Third, but not least, the massive use of carbon fossil sources unbalanced the concentration of gases in the atmosphere, with a rise in those that cause greenhouse effect and the consequent climate change. The whole situation is untenable and demands quick responses including the establishment of sweeping change in the procedures to fulfill the demands for fuels, lubricants, polymers and assorted materials required by the world's growing population.

The first initiatives to reconvert petrochemical processes include methodologies to produce bioethanol (from starch and soluble sugars) and biodiesel (from natural fats and oils). While these methods for first-generation biofuels are an important response, they have some associated drawbacks including the following (between others): (i) They generate sub-products needing recycling; (ii) the "bio" component is limited mainly to the starting material, but the rest of the process involves chemical methods with little use of biological tools; and (iii) the natural sources used are important feeding stock for humans, thus creating an ethic dilemma (employ resources for food or for fuels?). A broader vision which seeks to solve these critical issues, also using multifunctional strategies is given by the biorefinery approach (Kamm and Kamm, 2007). This approach includes the development of industrial biotechnology processes (not only for the production of fuels, but also to obtain energy, lubricants, polymers, as well as special chemicals) with use of raw materials with low or no nutritious value and the waste recycling. Thus, the objective is an integrated biorefinery for conversion 
of oil refineries, from sources and with procedures based (ideally entirely) on biological tools. Perhaps the ultimate goal of the biorefinery approach could be associated with developing technologies to reach something close to the "brown revolution" imagined by Spinrad (2008) in his science fiction short story.

Given the urgent demands for establishing strategies to produce goods and services in a framework of sustainability and friendly relationship with environment, the call for basic research in biochemistry and molecular biology has never been greater. Clearly, the development of appropriate biorefinery resources requires obtaining different cellular systems and biomolecules suitable for application in various industrial processes. The stage is set to develop new compounds that replace those currently derive from petroleum, with strategic benefit of being of renewable source and with high degree of (bio) degradability. It will be critical carry out studies to increase knowledge on the occurrence and regulation of metabolic pathways in different autotrophic and heterotrophic organisms; including exhaustive analysis of genomic data from many prokaryotes (e.g., anaerobic bacteria) as well as eukaryotes (as different algae, including diatoms). This will allow us to characterize mechanisms for synthesis of biomolecules having the physicochemical and rheological properties desirable to be used as plastics, plasticizers, lubricants, adhesives and many other applications. Also, these studies will contribute to identify pathways able to break down different functional chemical groups for their recycling and bioremediation. It is worth noting that the characterization of enzymes is an area of high potential, with the identification of different catalytic domains and the establishment of structure-to-function relationships to optimize the efficiency of different reactions and modify the affinity of proteins toward different molecules. Increasing understanding at the structural and functional biochemical level will strengthen the platform for the design of novel enzymes by approaches of theozyme/compuzyme type (Tantillo et al., 1998; Dechancie et al., 2007), complemented by practice of protein engineering. The latter will be a powerful tool to be used in combination with technology allowing us to construct living cells with a synthetic genome (Venter, 2013). In our view, relevant biotechnological advances would be developed within coming decades if the resources are properly invested to achieve these objectives, vital for the successful coexistence of humankind and earth.

\section{Acknowledgment}

The research thanks Drs. Hannah Sivak and Luciana Funtowicz for critical reading. AAI is a Superior
Investigator from CONICET and his work is supported by UNL, CONICET and ANPCyT.

\section{References}

Dechancie, J., F.R. Clemente, A.J. Smith, H. Gunaydin and Y.L. Zhao et al., 2007. How similar are enzyme active site geometries derived from quantum mechanical theozymes to crystal structures of enzyme-inhibitor complexes? Implications for enzyme design. Protein Sci., 16: 1851-1866. PMID: 17766382

Joyce, B.L. and C.N. Stewart Jr, 2012. Designing the perfect plant feedstock for biofuel production: Using the whole buffalo to diversify fuels and products. Biotechnol. Adv., 30: 1011-1022. PMID: 21856404

Kamm, B. and M. Kamm, 2007. Biorefineries-Multi Product Processes. In: White Biotechnology, Ulber, R. and D. Sell, (Eds.), Springer Science and Business Media, Berlin, ISBN-10: 3540456953, pp: 175-204.

Lagerkvist, U., 2005. The Enigma of Ferment: From the Philosopher's Stone to the First Biochemical Nobel Prize. 1st Edn., World Scientific, Hackensack, ISBN-10: 9812564217, pp: 161.

Nobel Media AB, 2014. The Nobel Prize in Physiology or Medicine 1959. http://www.nobelprize.org/nobel_prizes/medicine /laureates/1959/

Nelson, D. and M.M. Cox, 2013. Lehninger Principles of Biochemistry, 6th Edn., W.H. Freeman, New York, ISBN-10: 1464109621, pp: 1198.

Spinrad, N., 2008. The brown revolution. Nature, 434: 256-256.

http://www.nature.com/nature/journal/v455/n7212 /full/455564a.html

Venter, J.C., 2013. Life at the Speed of Light: From the Double Helix to the Dawn of Digital Life. 1st Edn., Penguin Group US, New York, ISBN-10: 1101638028, pp: 240.

Watson. J.D. and F.H. Crick, 1953. Molecular structure of nucleic acids: A structure for deoxyribose nucleic acid. Nature, 171: 737-738. DOI: $10.1038 / 171737 \mathrm{a} 0$

Tantillo, D.J., J. Chen and K.N. Houk, 1998. Theozymes and compuzymes: Theoretical models for biological catalysis. Current Opin. Chem. Biol., 2: 743-750.

DOI: $10.1016 / \mathrm{S} 1367-5931(98) 80112-9$

Yeh, B.J. and W.A. Lim, 2007. Synthetic biology: Lessons from the history of synthetic organic chemistry. Nature Chem. Biol., 3: 521-525. PMID: 17710092 